\title{
Introduction: A New Look at Environmental Crime
}

\author{
Rachel Armitage
}

Published online: 1 April 2011

(C) Springer Science+Business Media B.V. 2011

The concept for this special edition was conceived during the Green Criminology panel at the European Society of Criminology Conference in Ljubljana, Slovenia, 2009. With contributions from Australia, England and the USA and papers that present techniques for identifying emerging threats, methods for preventing and reducing those threats and a framework for raising the prominence of environmental crime, this edition represents a truly international and multidisciplinary contribution to the field.

"A New Look at Environmental Crime". Environmental Crime focuses upon crimes and harms against the environment and nonhuman animals and encompasses green criminology, conservation criminology and wildlife crime as well as sustainability and climate change. This special edition represents a new look because these papers consider new methods for identifying threats, new approaches to reducing environmental crime and new ways of presenting the problem. Through horizon scanning to highlighting emerging threats, through the application of situational crime prevention techniques to aid prevention and by framing environmental crime reduction in terms of carbon costs to society, the task appears more achievable, and the priority placed upon these crimes/harms becomes more fundamental.

This edition of the journal begins with White and Heckenberg's paper "Environmental Horizon Scanning and Criminological Theory and Practice". The paper sets out a mechanism for identifying threats that may arise and potential strategies to mitigate or adapt to those threats. Using a selection of examples of key issues within ecoglobal criminology, the authors map out methodological principles and practical measures that can be harnessed to carry out horizon scanning. The three stages of horizon scanning (theorising the causal factors, employing multidisciplinary methods and deliberating on potential policy responses) allow researchers to gather ideas and evidence from a variety of different sources and disciplines to identify where harms and risks are emerging and to develop pre-emptive strategies to prevent future harm. White and Heckenberg conclude by offering a series of recommendations to encourage the academic community to invest more

R. Armitage $(\square)$

Applied Criminology Centre, University of Huddersfield, HHR02/01, Queensgate, Huddersfield HD1 3DH, UK

e-mail: r.a.armitage@hud.ac.uk 
effort in identifying and considering future environmental harms and crimes. These include regular horizon scanning slots at conferences, opinion pieces in journals, routine collation and dissemination of findings and identifying funding for future-oriented research.

In her paper "Wildlife Crime: The Problems of Enforcement", Wellsmith considers the problem of relying on an enforcement approach for controlling wildlife crime (and wider offences against the environment) and outlines alternative forms of control. Focusing upon the current response to one area of environmental crime (wildlife crime) in England and Wales, Wellsmith outlines the legislative framework that criminalizes harm or exploitation of wildlife and the main enforcement methods used. The paper critically assesses the problems facing the enforcement approach, including the underresourcing and marginalisation of this area of crime and the response to it; the large, dark figure of wildlife crime; the possibility of corruption amongst those responsible for enforcing legislation (particularly in developing countries); the lack of seriousness attached to wildlife crimes; and the limited deterrent effect - due to the lack of certainty of detection and any associated punishment. Through a detailed review of research within the field of environmental crime, the author highlights how it is estimated that approximately $10 \%$ of known environmental crimes end up in court and that a large proportion of offences never come to the attention of the authorities. She further highlights how the severity of punishment (if caught) rarely outweighs the financial benefits associated with such offending - highlighting a study by Akella and Cannon (2004) that found that the economic disincentive of punishment for such offences varied from $\$ 0.09$ to $\$ 6.44$, with profits ranging from $\$ 70.57$ to $\$ 91,967.36$ (Akella and Cannon, 2004). With risk of detection (certainty) low and the financial benefits outweighing the potential costs (severity), the key factors upon which the deterrent principle relies are not being met in relation to wildlife crime. Wellsmith questions why those mandated to reduce environmental crimes have focused upon enforcement at the expense of alternative approaches. As well as proposing methods to improve the current enforcement of environment legislation (including increased funding, enhanced publicity, increasing the certainty of detection and ensuring that punishment is commensurate with harm), the paper outlines alternative forms of control, including offering viable noncrime alternatives to those involved in wildlife crime and moving away from an enforcementbased response to place a greater emphasis on prevention - particularly the methods used in situational crime prevention. As Wellsmith highlights, preventing a crime from taking place is always preferable to relying upon detection and punishment after the crime has occurred. However, for wildlife crime, where the harm may result in extinction and the loss of a species, prevention is more crucial to reduce such risks. The author contends that criminology can contribute to the field of environmental crime through a healthy scepticism regarding the effectiveness of general and individual deterrence as a means of crime control and through offering alternative approaches to its reduction.

In their paper "Preventing Wildlife Crime: Solutions that can Overcome the 'Tragedy of the Commons",, Pires and Moreto continue the theme of applying situational crime prevention techniques to the reduction of wildlife crime. The authors highlight how a common response to reducing wildlife crime has been the creation of laws and international trade agreements and how this approach has failed to take account of the fact that the majority of offenders are local (as opposed to organised crime groups) whose motivation is financial and often opportunistic. Other flaws in the regulatory approach include the lack of certainty of detection and prosecution (given the limited resources and potential for corruption amongst law enforcement officials); the absence of capable guardians in the majority of locations in which these offences take place (largely open land or sea); and the unintended consequences that, in many cases, have 
resulted in rising prices for animals purchased on the black market. Pires and Moreto argue that the application of situational crime prevention to wildlife crime presents a "unique and viable" approach to its reduction. They argue that the opportunistic factors that facilitate wildlife crime are much the same as those for the more traditionally considered property crime, including accessibility and abundance. The paper highlights how the principles of situational crime prevention allow interventions to be tailored to the specific local context of an area - accounting for differences in the local community, illegal market and environmental features. Using the three case-study wildlife crime problems of parrot poaching, wildlife skins and illegal, unreported and unregulated fishing, the authors highlight innovative crime prevention solutions aimed at incentivising locals not to commit these crimes and making it more difficult for them to do so. Under the former, the paper presents several community-based sustainable management programmes such as the establishment of ecotourist lodges that offer locals a financial incentive to stop poaching and to act as capable guardians to protect their livelihood (the local wildlife that is attracting tourists to the area). Interventions aimed at making it more difficult to commit wildlife crime include a scheme to label/ certify skins that are obtained in a permitted manner, from communities that participate in sustainable management practices, therefore reducing the market value of skins that are not certified.

In the final paper, Farrell and Pease discuss the carbon costs of crime and the role of crime prevention in addressing one of the most urgent social harms - climate change. The authors demonstrate how: "The contingent costs resulting from destruction or theft of property requiring its replacement, and criminal harms to people requiring treatment, and the energy cost of both in emergency services and criminal justice response to crime events, taken together, represent the carbon cost of crime". They tentatively calculate the carbon costs of crime in the UK and Europe, estimating the cost in England and Wales to be an annual minimum of $6,000,000$ tonnes of carbon dioxide $\left(\mathrm{CO}_{2}-\right)$, this without factoring in the carbon cost of moving home (a decision many make based upon their experiences, fears and perceptions of crime and disorder within their neighbourhood). Farrell and Pease highlight how the link between crime and climate change has been largely absent from literature and policy within the sustainability and green criminology debates. The paper contends that one reason for this "blind spot" has been that both politicians and the general public find it difficult to conceive how crime can be prevented without resulting in a police state - the general belief being that crime prevention equates to closed-circuit television (CCTV), barbed wire and barred windows. The paper usefully dispels this myth, outlining the role that situational crime prevention and crime prevention through environmental design can play in preventing crime and disorder and reducing the fear of crime. Whereas crime may play a key part in reducing the longevity of natural resources and subsequently increasing $\mathrm{CO}_{2}$ emissions, crime prevention can play an equal role in increasing the longevity of natural resources and reducing society's impact on climate change. The authors contend that recognising the link between crime and climate change (and hence crime prevention and sustainability) could profoundly influence both social and criminal justice policy. Recognising that crime reduction measures can be designed into properties, products and services without a negative impact upon their design quality or their cost to consumers could (and should) increase the prominence of this issue within both green criminology and sustainability agendas.

It has been a pleasure to edit this special edition and to work alongside such dedicated researchers. It is hoped that the discussion presented throughout these papers will lead to further research and future collaborations. 